\title{
8
}
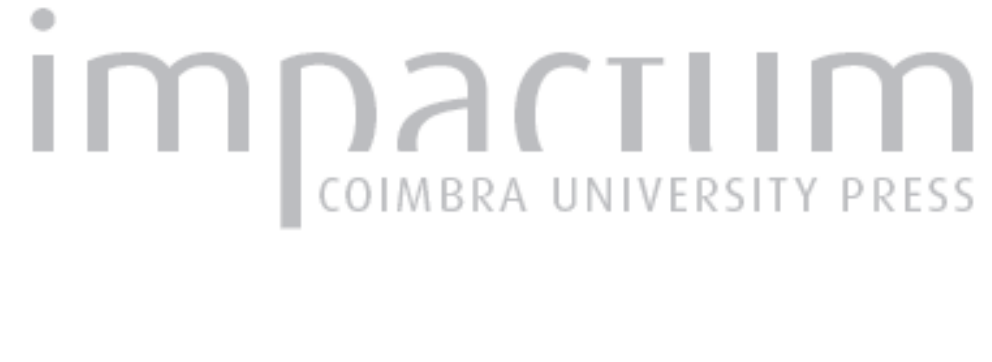

\section{Dilemas éticos do consentimento informado em ciências forenses}

Autor(es): $\quad$ Rosa, Bárbara Santa; Pereira, André Dias; Corte-Real, Francisco

Publicado por: Imprensa da Universidade de Coimbra

URL persistente:

URl:http://hdl.handle.net/10316.2/33263

DOI:

DOI:http://dx.doi.org/10.14195/1647-8630_23_5

Accessed : $\quad$ 26-Apr-2023 15:16:23

A navegação consulta e descarregamento dos títulos inseridos nas Bibliotecas Digitais UC Digitalis, UC Pombalina e UC Impactum, pressupõem a aceitação plena e sem reservas dos Termos e Condições de Uso destas Bibliotecas Digitais, disponíveis em https://digitalis.uc.pt/pt-pt/termos.

Conforme exposto nos referidos Termos e Condições de Uso, o descarregamento de títulos de acesso restrito requer uma licença válida de autorização devendo o utilizador aceder ao(s) documento(s) a partir de um endereço de IP da instituição detentora da supramencionada licença.

Ao utilizador é apenas permitido o descarregamento para uso pessoal, pelo que o emprego do(s) título(s) descarregado(s) para outro fim, designadamente comercial, carece de autorização do respetivo autor ou editor da obra.

Na medida em que todas as obras da UC Digitalis se encontram protegidas pelo Código do Direito de Autor e Direitos Conexos e demais legislação aplicável, toda a cópia, parcial ou total, deste documento, nos casos em que é legalmente admitida, deverá conter ou fazer-se acompanhar por este aviso.

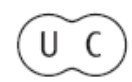


REVISTA PORTUGUESA

$\stackrel{\infty}{\cdots}$

$\stackrel{2}{i}$

$\dot{\bar{x}}$

$\bar{x}_{\bar{x}}$

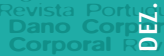

Oeno dorporal Revista Portuguesta do Dano Corporal Revista Portuguens do Dano Corporal

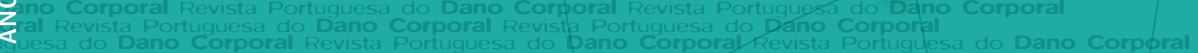

Rvista Portuguesa do Dano Corporal Revista Portuguesa do Dano Corporal Revista Portuguesa do pang Coporal

NPortuguesa do Dano Corporal Revista Portuguesd do Dano Corporal

Silo

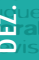

\section{APADAC}

ASSOCIAÇÃO PORTUGUESA

DE AVALIAÇÃO

DO DANO CORPORAL

INSTITUTO NACIONAL

DE MEDICINA LEGAL, I.P.

DELEGAÇÃO DO CENTRO 


\section{Dilemas éticos do consentimento informado em Ciências Forenses}

Bárbara Santa Rosa(1), André Dias Pereira(2), Francisco Corte-Real ${ }^{(1,3)}$

\section{INTRODUÇÃO}

A prática médica engloba actividades tão diversas quanto complexas. A sociedade exige não só médicos que representem os interesses de saúde das populações, mas também médicos capazes de intervir na resolução de problemas que transcendem este papel, nomeadamente em situações ou acontecimentos com dignidade jurídica.

Assim, o médico poderá ser chamado a actuar como perito, ao serviço da Justiça, cumprindo o objectivo de estabelecer, por meio de obtenção de provas, a veracidade ou falsidade dos factos alegados. A perícia é de especial importância devido ao seu carácter de cientificidade, impessoalidade e objectividade.

As singulares características do exame pericial colocam muitas vezes o médico em situações de conflito entre os interesses do examinando e os interesses do sistema judicial. Este conflito, por si só, não é ilegítimo. É no entanto exigível que o perito seja capaz de o resolver adequadamente, sem se afastar da leges artis, imperando que tenha a sensibilidade necessária para o perceber. É também de crucial importância que se certifique, antes de intervir, que o examinando tem conhecimento da sua qualidade de perito, da missão que está a desempenhar e da sua obrigação de comunicar à entidade requisitante os resultados do exame.

\footnotetext{
1 Instituto Nacional de Medicina Legal e Ciências Forenses, Delegação do Centro, Coimbra, Portugal

2 Faculdade de Direito, Universidade de Coimbra, Coimbra, Portugal

3 Faculdade de Medicina, Universidade de Coimbra, Coimbra, Portugal
} 
A ars médica exige, como recorda Walter Osswald "o encontro entre uma confiança e uma competência". Se só houver a competência do médico, sem um verdadeiro encontro interpessoal, o acto médico é uma prática técnica desumanizada e a própria confiança, o outro elemento deste binómio, corre o risco de perder-se (Vilaça Ramos 2011).

Acresce que os médicos, pela natureza peculiar da sua actividade, que se dirige a pessoas como pessoas e não meramente como cidadãos, sentiram, desde sempre, a necessidade de ter preceitos próprios, que os protegessem da tentação de abusar do seu "poder" (Serrão 2008). Um dos mais importantes preceitos, que se vê frequentemente comprometido por ordens judiciais, é o do dever de obtenção de consentimento informado.

Muitas vezes o perito, com o intuito de corresponder às expectativas do sistema judicial, sente-se pressionado a realizar o exame forense sem o consentimento, ou mesmo contra a vontade do examinando. No entanto no Código Deontológico da Ordem dos Médicos, é inequivocamente afirmado que o perito deve realizar a sua actividade submetendo-se às considerações deste Código, ou seja, não é estabelecido um regime de excepção para a actividade pericial (Corte Real 2011). Assim o dever de informar faz parte da responsabilidade ética do perito, sendo este um pré-requisito para o consentimento e a legitimidade do acto pericial. Impõe-se o respeito pelos direitos do examinando, não podendo o perito médico subjugar-se, sem mais, a uma ordem do tribunal, que muitas vezes os contraria.

O Relatório de Belmont (1987), fundamentando-se na ideia de que os conflitos morais poderiam ser medidos pela referência a algumas ferramentas morais, os chamados princípios éticos, estabeleceu os "Princípios e directrizes éticas para a protecção de pacientes Humanos em pesquisas". Inspirados por este documento Beauchamp, que tinha participado na sua elaboração, e Childress, propõem a Teoria Principialista, que estabelece os quatro princípios da ética médica: autonomia, beneficência, não maleficência e justiça. A estes princípios estão subjacentes quatro regras essenciais: veracidade, fidelidade, confidencialidade e privacidade.

Kant afirmou, a propósito da moralidade, que "a ação capaz de subsistir com a autonomia da vontade, é permitida, a que não concorda com ela é proibida". É assim de salientar que o princípio do respeito pela autonomia afirma a capacidade do indivíduo para a autodeterminação. A pessoa tem o direito de agir de acordo com as suas próprias convicções. Tal não significa apenas a abstenção de interferir nas escolhas individuais, mas também a obrigação moral de promover condições que permitam uma tomada de decisão autónoma (Meneses 2007). Jonh Dewey clarifica esta ideia afirmando que "um princípio ético não é uma ordem para o sujeito agir ou se abster 
de agir de determinada maneira, é antes uma ferramenta para analisar uma determinada situação em especial, determinando-se o certo e o errado pela situação na sua totalidade e não por uma regra geral".

Não obstante a importância histórica da Teoria Principialista, esta é nalguns casos claramente insuficiente, quando falamos da prática pericial do médico. O perito lida com pessoas particularmente fragilizadas, de acordo com o seu estado de sofrimento ou temor à autoridade judicial, o que acentua a assimetria da relação médico-examinando do ponto de vista emocional e eleva a exigência ética no desempenho desta actividade. Resulta do exposto a fragilidade do principal mecanismo regulador do Principialismo, o consentimento, para por si só garantir a ética na actividade pericial. Isto é particularmente verdade quando falamos de examinandos sob custódia judicial, já que tal circunstância pode provocar sentimentos de medo e impotência que influenciam o agir autónomo da pessoa, no seu querer.

Nietzche afirma que "o querer parece qualquer coisa de complexo, algo que só constitui uma unidade enquanto palavra. Em cada querer há em primeiro lugar uma pluralidade de sentimentos, a saber, o sentimento da situação de onde se partiu, o sentimento da situação para onde se vai e o sentimento destes mesmos "de" e "para" (...)" (Nietzsche 1996).

Assim devemos considerar que a vulnerabilidade do examinando pode diminuir a sua capacidade de autodeterminação, sobretudo no que se refere ao consentimento livre e esclarecido. Mas a vulnerabilidade não significa necessariamente a redução da autonomia, prende-se antes com a relação de desigualdade entre dois indivíduos e com uma condição diminuída, senão anulada, de um deles manifestar a sua vontade. Este facto é suficiente para inspirar outras referências éticas de protecção e respeito pelos direitos do examinando, dedignadamente a dignidade humana, a responsabilidade, a integridade, a privacidade, a solidariedade, a tolerância, a não discriminação e a não estigmatização, a fim de que haja justiça - equidade. Justiça essa, que encontra a sua origem entre homens pouco mais ou menos com igual poder, como bem entendeu Tucídides (na tremenda conferência dos legados atenienses e mélicos); onde não haja uma supremacia claramente reconhecível, e um combate redundaria em prejuízo vão e recíproco (...)" (Nietzsche 1996).

O conceito de dignidade humana é entre nós reafirmado, desde a revisão da Constituição da República Portuguesa em 1997, pelo $n^{\circ} 3$ do artigo $26^{\circ}$ que prescreve que a "lei garantirá a dignidade pessoal (...)". Segundo Beauchamp e Childress a dignidade humana é um valor intrínseco da pessoa e constitui condição sine qua non, para que se respeite a pessoa humana em si e não apenas a sua autonomia (Neto 2006). 
A relação entre o princípio da autonomia e da dignidade da pessoa não é clara. No entanto, o princípio da dignidade prevalece sobre o da autonomia, podendo justificar restrições voluntárias a essa autonomia (Neto 2006).

Partindo destes pressupostos consideramos pertinente reflectir sobre algumas questões: poderá nalguma situação justificar-se a realização de perícias médico-legais sem o consentimento do examinando, para assegurar meios de prova? Deverá o perito realizar procedimentos sem indicação médica, durante um exame pericial, se o examinado consentir? O facto do examinando ser a vítima ou o suspeito deverá relevar na tomada de decisão do perito médico?

Se estas questões se enraízam em princípios inquestionavelmente éticos, as soluções deverão não só contempla-los, mas transcende-los. Emerge a necessidade de harmonizar os preceitos deontológicos do perito com a legislação vigente.

\section{OBJECTIVOS}

Afirma Aristóteles que o "Homem é por natureza um animal político", denunciando a sua necessidade de viver em sociedade. Podemos acrescentar que é também um animal jurídico. Desde muito cedo as colectividades humanas orientam-se por elencos normativos, escritos ou como parte de tradições de carácter oral, os quais influenciam a forma como a sociedade se organiza e resolve as questões decorrentes das interacções que contempla. O Homem decide o carácter lícito e ilícito das condutas e constrói formas de convivência que podem ser alteradas no decorrer do tempo ou permanecer quase imutáveis.

Designamos o Direito válido, que exerce o seu domínio e império sobre a sociedade, Direito positivo. O positivismo confunde o Direito com a lei, abrangendo o conjunto de regras jurídicas que se encontram em vigor num determinado Estado, num dado momento. Fala-se assim de jus in civitate positum, em contraste com a noção de Direito natural que consiste num ordenamento de carácter ideal, numa ideia abstracta acerca do Direito, simbolizando o sentimento de justiça vigente na sociedade. É precisamente ao Direito natural que se subordinam os princípios éticos.

Do positivismo jurídico resultam lacunas ou omissões legislativas. Assim em certos casos o julgador depara-se com a ausência de norma reguladora que discipline uma conduta concreta, posta sobre a sua apreciação. Este fenómeno é frequente quando abordados temas relacionados com a Bioética, consequência da complexidade desta disciplina. Em matérias de Bioética, nas quais se inclui o consentimento informado, é difícil estabelecer um consenso 
aplicável transversalmente em qualquer circunstância que as invoque. Parece-nos neste âmbito que o mais importante não é definir condutas precisas mas sim orientações que permitam tomar decisões jurídica e deontologicamente aceitáveis (a este objectivo subordinámos o nosso artigo).

\section{ALGUNS PRESSUPOSTOS JURÍDICOS DA ACTIVIDADE PERICIAL}

As características do exame pericial impõem importantes constrangimentos, não só do ponto de vista deontológico mas também legal, na sua execução.

Comecemos por analisar as particularidades do consentimento informado quando comparamos a actividade médica pericial com as intervenções médico-cirúrgicas de índole terapêutica.

Estabelece o artigo $150^{\circ}$ do Código Penal a atipicidade, em termos de ofensa à integridade física, das intervenções ou tratamentos com intuito preventivo ou curativo. ${ }^{4}$ No entanto estas condutas podem lesar o bem jurídico liberdade, se não for respeitado o artigo $156^{\circ}$ que impõe o dever de obter o consentimento do doente ${ }^{5}$. $\mathrm{O}^{\circ} 2$ deste artigo alude ao consentimento presumido, considerando lícita a intervenção sem o consentimento do doente, designadamente se este se encontra inconsciente, quando não se verificarem circunstâncias que permitam concluir com segurança que o consentimento seria recusado.

Em contrapartida a actividade médica pericial reveste-se de intenção distinta, a de reunir meios de prova. Não promove, em princípio, qualquer benefício para a saúde do examinando. Assim a intervenção do perito médico não resulta atípica no que se refere a ofensa da integridade física. Importa aqui considerar o artigo $149^{\circ}$, o qual estabelece que para efeito de consentimento, a integridade físicas se considera livremente disponível, desde que a ofensa ao corpo ou à saúde não contrarie os bons costumes,

4 Art. $150^{\circ}$ do Código Penal 1. As intervenções e os tratamentos que segundo o estado dos conhecimentos e da experiência da medicina, se mostrarem indicados e forem levados a cabo, de acordo com as leges artis, por um médico ou por outra pessoa legalmente autorizada, com intenção de prevenir, diagnosticar debelar ou minorar doença, sofrimento, lesão ou fadiga corporal, ou perturbação mental, não se consideram ofensa à integridade física.

5 Art. $156^{\circ}$ do Código Penal 1- As pessoas indicadas no artigo $150^{\circ}$ que, em vista das finalidades nele apontadas, realizarem intervenções ou tratamentos sem consentimento do paciente são punidas com prisão até três anos ou com pena de multa. 2- O facto não é punível quando o consentimento: a) Só puder ser obtido com adiamento que implique perigo para a vida, o corpo ou a saúde; e não se verificarem circunstâncias que permitam concluir com segurança que o consentimento seria recusado 3- Se, por negligência grosseira, o agente representar falsamente os pressupostos do consentimento, é punido com pena de prisão até 6 meses ou com pena de multa até 60 dias $4-(.$. 
tomando-se em conta, nomeadamente, os motivos e os fins do agente ou do ofendido, bem como os meios empregados e a amplitude previsível da ofensa. É também aplicável o artigo $39^{\circ}$ que fala no consentimento presumido $^{6}$ de uma forma mais generalista, contemplando aquelas situações que permitem razoavelmente supor que o titular do interesse juridicamente protegido teria eficazmente consentido no facto, se conhecesse as circunstâncias em que este é praticado.

Há também que distinguir relatório pericial de relatório médico, revestindo-se estes documentos de distinto valor probatório. Um diagnóstico clínico efectuado por um médico hospitalar constitui apenas uma descrição que, embora baseada em evidências médicas, não encerra a componente explicativa da metodologia pericial. Documenta um facto mas não fornece os elementos necessários à aplicação da lei pela autoridade judiciária (gravidade da lesão; sequelas; nexo de causalidade entre a agressão, a lesão e o dano; identificação do objecto usado na agressão), sendo insuficiente para a subsunção do facto no respectivo tipo legal de crime (Magalhães s.d.). Constitui, portanto, um documento a ser valorado em sede de prova documental, não se lhe aplicando as regras excepcionais da valoração da prova pericial em processo penal.

De facto consta do artigo $127^{\circ}$ do Código de Processo Penal que a entidade competente aprecia as provas segundo as regras da experiência e a sua livre convicção. No entanto afirma o artigo $163^{\circ}$ do mesmo Código que se presume subtraído à livre apreciação do julgador o juízo técnico, científico ou artístico inerente à prova pericial. Esta excepção evidência a importância probatória da perícia.

A realização de actos periciais urgentes ${ }^{7}$ justifica-se, no âmbito da Medicina Legal, pela necessidade de preservar meios de prova que possam perder-se ou deteriorar-se. Assim, este tipo de perícia, pode ser requerida directamente aos serviços médico-legais pela vítima ou pelo seu representante legal, bem como pelo profissional de saúde que primeiro contacte com ela. Este facto tem importantes implicações legais, uma vez que nestes casos não existe um processo de inquérito penal prévio ou uma denúncia de crime a órgão

\footnotetext{
6 Considera-se equiparado ao consentimento efectivo

7 Artigo $13^{\circ}$ da lei 45/2004, de 19 de Agosto (realização de perícias urgentes) 1- Consideram-se perícias médico-legais urgentes aquelas em que se imponha assegurar com brevidade a observação de vítimas de violência, tendo designadamente em vista a colheita de vestígios ou amostras susceptíveis de se perderem ou alterarem rapidamente, bem como o exame do local em situações de vítimas mortais de crime doloso ou em que exista suspeita de tal.
} 
de polícia criminal, actuando os serviços médico-legais com competências similares à dos órgãos de polícia criminal ${ }^{8}$.

Nas Delegações existe um perito médico, de prevenção, que assegura a realização dos exames médico-legais urgentes a qualquer hora do dia e em qualquer dia da semana. Nas áreas territoriais servidas pelos Gabinetes Médico-Legais, fora dos dias e horários úteis, será necessário transferir o examinando para um Hospital Central, à semelhança do que acontece noutras situações de índole clínica, para realização da perícia. Nos casos em que a transferência não seja possível deve o médico hospitalar proceder à recolha e preservação dos vestígios, podendo solicitar apoio por telefone ao perito de prevenção na respectiva Delegação. Compete-lhe também sinalizar o caso, enviar as amostras colhidas para a Delegação da respectiva área e orientar o examinado para o Gabinete Médico-Legal onde deverá posteriormente ser sujeito a perícia médica.

Acresce às singularidades acima expostas que a jurisdição Portuguesa, através do artigo $6^{\circ}$ da Lei 45/2004 de 19 de Agosto $^{9}$ e do artigo $172^{\circ}$ do Código do Processo Penal ${ }^{10}$, impõe o dever de sujeição a exame médico-legal. Presumem-se contemplados os princípios da proporcionalidade e da adequação

8 Artigo $4^{\circ}$ da lei 45/2004, de 19 de Agosto (denúncia de crimes) 1- As delegações e os gabinetes médico-legais do instituto podem receber denúncias de crimes, no âmbito da atividade pericial que desenvolvem, devendo remetê-las no mais curto prazo ao Ministério Público. 2- sempre que tal se mostre necessário para a boa execução das perícias médico-legais, as delegações e os gabinetes médico-legais do instituto podem praticar os actos cautelares necessários e urgentes para assegurar os meios de prova, procedendo nomeadamente, ao exame, colheita e preservação de vestígios, sem prejuízo das competências legais da autoridade policial à qual competir a investigação. 3- o disposto nos números anteriores é igualmente aplicável ao perito médico da delegação ou gabinete médico-legal do instituto cuja intervenção seja solicitada no âmbito do serviço de escala para a realização de perícias médico-legais urgentes.

9 Artigo $6^{\circ}$ Lei $\mathrm{n}^{\circ}$ 45/2004, de 19 de Agosto (Obrigatoriedade de sujeição a exames) 1- Ninguém pode eximir-se a ser submetido a qualquer exame médico-legal quando este se mostrar necessário ao inquérito ou à instrução de qualquer processo e desde que ordenado pela autoridade judiciária competente, nos termos da lei. 2- Qualquer pessoa devidamente notificada ou convocada pelo Director de Delegação do Instituto ou pelo Coordenador de Gabinete Médico-Legal para a realização de uma perícia deve comparecer, no dia, hora e local designados, sendo a falta comunicada, para os devidos efeitos, à autoridade judiciária competente.

10 Artigo $172^{\circ}$ do Código de Processo Penal (Sujeição a exame) 1- Se alguém pretender eximir-se ou obstar a qualquer exame devido ou a facultar coisa que deva ser examinada, pode ser compelido por decisão da autoridade judiciária competente 2- Os exames susceptíveis de ofender o pudor das pessoas devem respeitar a dignidade e, na medida do possível o pudor de quem a eles se submeter. Ao exame só assistem quem a ele proceder e a autoridade judiciária competente, podendo o examinando fazer-se acompanhar de pessoa da sua confiança. 
e considera-se que os bens e valores juridicamente tutelados pelo direito penal justificam, em regra, restrições à liberdade e integridade física e moral das pessoas envolvidas como agentes ou vítimas de um determinado crime. Nos casos de incumprimento do dever de sujeição a exame o examinando será punido por crime de desobediência ${ }^{11}$ (Pereira 2005). No entanto, a colheita compulsiva de amostras biológicas é considerada por muitos autores inconstitucional ${ }^{12}$, violando importantes direitos fundamentais tais como o princípio da dignidade da pessoa humana ${ }^{13}$, o direito à integridade física e moral ${ }^{14}$, o direito à livre disposição do seu corpo, o direito à incolumidade pessoal, o direito à reserva da intimidade da vida privada ${ }^{15}$ e o privilégio de não-auto-incriminação (princípio "nemo tenetur se ipsumaccusare") (Pereira 2005).

É também de considerar o artigo $124^{\circ}$ do Código Deontológico da Ordem dos Médicos que prescreve o dever do perito médico utilizar apenas os meios de exame estritamente necessários à sua missão e não prejudiciais ao examinando e de se abster de actuar sempre que este recuse formalmente deixar-se examinar.

\section{A CAPACIDADE PARA CONSENTIR}

A capacidade para consentir é geralmente presumida, considerando-se sempre que o examinando é capaz de modular o seu comportamento, comunicar de forma compreensível, recordar a informação que lhe é transmitida e não tenha sido interditado pelo tribunal (Roth 1977). No entanto os

11 Artigo $348^{\circ}$ do Código Penal (Desobediência): 1- Quem faltar à obediência devida a ordem ou a mandado legítimos, regularmente comunicados e emanados de autoridade ou funcionário competente, é punido com pena de prisão até 1 ano ou com pena de multa até 120 dias (...)

12 Artigo $32^{\circ} \mathrm{n}^{\circ} 8$ da Constituição da República Portuguesa São nulas todas as provas obtidas mediante tortura, coação, ofensa da integridade física ou moral da pessoa, abusiva intromissão na vida privada, no domicílio, na correspondência ou nas telecomunicações.

13 Artigo $1^{\circ}$ da Constituição da República Portuguesa: Portugal é uma República soberana baseada na dignidade da pessoa humana e na vontade popular e empenhada na construção de uma sociedade livre, justa e solidária, se não houver perigo na demora e devendo ser informado de que possui essa faculdade.

14 Artigo $25^{\circ}$ da Constituição da República Portuguesa 1- a integridade moral e física das pessoas é inviolável. 2- ninguém pode ser submetido a tortura nem a tratos ou penas cruéis degradantes ou desumanos.

15 Art $26^{\circ}$ da Constituição da República Portuguesa (Outros direitos pessoais): 1- A todos são reconhecidos os direitos(...) à reserva da intimidade da vida privada e familiar (...). 2- A lei estabelecerá garantias efectivas contra a utilizaçãoo abusiva ou contrária à dignidade humana de informações relativas às pessoas e famílias. 3- A lei garantirá a dignidade pessoal e a identidade genética do ser humano nomeadamente na criação, desenvolvimento e utilização das tecnologias e na experimentação científica. 
examinandos considerados capazes integram um largo espectro que vai desde os marginalmente capazes até aqueles que são particularmente informados, conhecedores e críticos da sua situação e perspectivas futuras (Wear 2004).

Subjacente à obtenção do consentimento, encontra-se o dever de informar, o qual recai sobre o médico. Considera Descartes que age com maior liberdade quem melhor compreende as alternativas em escolha. Esclarece Kant que a vontade é uma espécie de causalidade dos seres viventes, enquanto dotados de razão, sendo a liberdade uma propriedade desta causalidade, que permite agir independentemente de causas estranhas que a determinem. Estes pressupostos são essênciais para respeitar a autonomia que é, segundo o filósofo, essencial ao princípio da dignidade da natureza humana (Kant 1785). Importa que a decisão do examinando seja informada e livre.

O examinando deve ser informado, previamente ao exame, sobre os aspectos forenses e médicos do processo, podendo consentir essas duas vertentes ou apenas uma. Deve ser-lhe explicado que o consentimento forense implica não só a permissão de realização do exame e consequente recolha de evidências, registo fotográfico e/ou exames complementares toxicológicos e genéticos mas também a notificação das autoridades judiciárias e consequente acesso à informação, possíveis contactos futuros por razões relacionadas com a investigação criminal e notificação no caso de identificação do suspeito.

No entanto, o examinando pode ser juridicamente incapaz de consentir, por razões de idade ou anomalia psíquica, nomeadamente por doenças mentais, transtornos cognitivos, intoxicação aguda (alcoólica ou por outras drogas) ou eventos traumáticos ou clínicos agudos que cursem com alterações da consciência. Nestes casos deve o médico perito considerar múltiplos factores na decisão de realizar ou não o exame pericial (Carr 2010).

\section{Os menores de 16 anos e os adultos com capacidade diminuida}

Encontra-se expresso no n. ${ }^{\circ} 3$ do artigo $38^{\circ}$ do Código Penal que o consentimento só é eficaz se for prestado por quem tiver mais de 16 anos e possuir discernimento necessário para avaliar o seu sentido e alcance no momento em que o presta. Este artigo respeita o princípio da autonomia progressiva da criança ou jovem, implícito também no $\mathrm{n}^{\circ} 2$ do artigo $1878^{\circ}$ do Código Civil ${ }^{16}$. Considera-se então que a partir dos 16 anos os menores

16 Artigo $1878^{\circ}$ do Código Penal (Conteúdo do poder paternal) 1. Compete aos pais, no interesse dos filhos, velar pela segurança e saúde destes, prover o seu sustento, dirigir a sua educação, representá-los, ainda que nascituros, e administrar os seus bens 2. Os filhos devem obediên- 
escapam à necessidade de intervenção protectora do poder paternal, em assuntos relacionados com a assistência médica, criando como que uma "maioridade especial" para o acesso a cuidados de saúde. Se o menor não tem discernimento suficiente, o que será a regra no caso dos menores de 14 anos, as intervenções de saúde devem ser precedidas pelo consentimento dos detentores do poder paternal (Pereira 2004).

No caso do exame pericial, apesar das suas características próprias, pode aceitar-se, de acordo com a idade (a partir dos 14 anos) e capacidade de entendimento, que o menor possa consentir ou dissentir a perícia sem o conhecimento dos pais. Parece-nos no entanto que um evento que cause a necessidade de uma avaliação médico-legal, nomeadamente abuso sexual ou maus tratos, gera um importante conflito emocional. A imaturidade subjacente à idade determina maior dificuldade na gestão do impacto destas situações, o que pode condicionar a interpretação da perícia como um estímulo aversivo, levando necessariamente a condutas de evitamento. É aqui de extrema importância uma explicação detalhada dos procedimentos forenses e dos seus objectivos e concomitante receptividade ao esclarecimento de dúvidas, quebra de mitos e compreensão dos medos e incertezas do examinando menor. É essencial ter em conta, bem como proteger, a vulnerabilidade da criança ou jovem.

No caso de menores de 16 anos, se os pais (ou quem possui a guarda de facto) consentem a realização do exame, mas a criança recusa, opondo-se activamente à realização do mesmo, não parece viável forçar o menor. Ainda que um exame pericial possa ser realizado contra a vontade do examinando, é difícil aceitar que o médico perito não respeite, durante a sua intervenção, o bem estar físico e psíquico do examinando (Corte-Real 2011). Nestes casos deve explicar-se ao representante legal que a denúncia do crime será feita ao Ministério Público, para que este possa exercer a acção penal. No relatório pericial constará que não se realizou exame físico devido à ausência de colaboração por parte do examinando. Deverão, no entanto, ser procuradas e usadas em tribunal outro tipo de provas.

Os interditos por anomalia psíquica consideram-se incapazes para consentir, excepto se a causa da interdição for apenas surdez-mudez ou cegueira. Os

cia aos pais; estes, porém, de acordo com a maturidade dos filhos, devem ter em conta a sua opinião nos assuntos familiares importantes e reconhecer-lhes autonomia na organização da própria vida. 
inabilitados não se presumem incompetentes, a não ser que a sentença de inabilitação imponha o oposto.

Em regra, nestes casos, existe já um substituto legal, o tutor ou curador, que pode recusar o exame médico-legal. No entanto a pessoa incapaz (para consentir) deve, na medida do possível, participar no processo de autorização, encontrando-se este facto explicitado no $\mathrm{n}^{\circ} 3$ do artigo $6^{\circ}$ da Convenção dos Direitos do Homem e da Biomedicina (Pereira 2004). Reserva-se ao Tribunal o direito de não concordar com a decisão quando a recusa for injustificada (Carr 2010).

Destes factos decorre que o médico perito pode ser confrontado com o dilema de realizar ou não o exame quando o tutor do adulto declarado incapaz ${ }^{17}$, ou no caso dos menores ${ }^{18}$ o pai ou quem tenha a guarda de facto, não possa ser contactado em tempo útil, seja o alegado agressor, ou haja fortes razões para suspeitar que o bem estar da criança ou adulto incapaz está ameaçado ${ }^{19}$.

Nestes casos atribui-se um carácter excepcional ao consentimento pelo representante legal, devendo o perito médico assegurar a colheita e preservação dos vestígios. O juiz poderá, se assim entender, nomear um tutor

17 No projecto lei $n^{\circ} 788 / \mathrm{X}$ (Partido Socialista) sobre "Direitos dos doentes à informação e consentimento informado" refere o artigo $12^{\circ} 1$. Considera-se adulto com capacidade diminuída a pessoa que no momento da decisão, devido a qualquer causa, não tem o discernimento suficiente para entender o sentido do seu consentimento, ou não tem livre exercício da vontade 2 . O poder da representação será exercido pelo procurador de cuidados de saúde, previamente designado pelo doente 3 . Na falta de procurador de cuidados de saúde, os adultos com capacidade diminuída são representados pelo seu tutor 4. Na ausência de qualquer dos representantes mencionados nos números anteriores, o médico actua segundo o consentimento presumido do doente, ouvidos, sempre que possível, o médico de família do doente e outras pessoas que tenham mantido com o doente relações de grande proximidade, designadamente os familiares.

18 No projecto lei $n^{\circ} 788 / \mathrm{X}$ (Partido Socialista) sobre "Direitos dos doentes à informação e consentimento informado" refere o artigo $13^{\circ}$ (representação de crianças e jovens) 1 . As crianças e jovens são representadas pelos seus representantes legais 2. A partir dos doze anos o jovem deve ser informado, na medida das suas capacidades de entendimento e a sua opinião deverá ser tomada em consideração como um factor cada vez mais determinante, em função da sua idade e do seu grau de maturidade. 3. Sem prejuízo do que está previsto em legislação especial, o jovem com idade igual ou superior a dezasseis anos, que possua capacidade de entendimento do sentido e alcance da sua decisão, tem o direito de consentir ou de recusar a intervenção médica, desde que esta não implique risco elevado de incapacidade grave ou de morte 4. Nos casos previstos na parte final do número anterior, a autorização é prestada pelos representantes legais, salvo o exercício do direito de veto pelo jovem.

19 Esta suspeita deve ter em conta a anamnese e os dados objectivos fornecidos pelo médico especialista que procedeu ao exame clínico do examinando, normalmente no Serviço de Urgência. 
temporário. É ainda de considerar a pertinência de accionar os serviços de protecção da vítima.

No que se refere aos menores prescreve o artigo $3^{\circ}$ da Lei de protecção de crianças e jovens em perigo que a intervenção de promoção e protecção tem lugar quando os pais, o representante legal ou quem tenha a guarda de facto ponham em perigo a sua segurança, saúde, formação, educação ou desenvolvimento, ou quando esse perigo resulte de acção ou omissão de terceiros ou da própria criança ou do jovem e aqueles não se oponham de modo adequado a removê-lo. Considera-se que a criança ou jovem está em perigo quando se verificam situações de maus tratos físicos e psíquicos, abusos sexuais, imposição de actividade ou trabalho excessivo ou inadequado à idade e situação pessoal da criança ou jovem ou prejudicial à sua formação ou desenvolvimento, sujeição directa ou indirecta a comportamentos que afectem gravemente a sua segurança ou o seu equilíbrio emocional e ausência de oposição adequada a remover comportamentos actividades ou consumos que afectem gravemente a sua saúde, segurança, formação, educação ou desenvolvimento.

O objectivo destes procedimentos é promover os direitos e proteger as crianças e os jovens, garantindo o seu bem estar e desenvolvimento integral. Assim o tribunal pode, sempre que necessário, intervir contra a vontade dos pais, do representante legal ou de quem tem a guarda de facto da criança ou do jovem, ou deste se tiver idade igual ou superior a 12 anos $^{20}$.

\section{A vítima inconsciente (ou com importante compromisso cognitivo)}

Há alguns anos, no estado do Minnesota uma vítima de abuso sexual processou o Hospital e a equipe de saúde que a observou por não se ter procedido à recolha e preservação de evidências forenses. Esta importante omissão deveu-se ao facto da examinanda se encontrar em estado dissociativo quando deu entrada no Serviço de Urgência e consequentemente incapacitada

20 Lei de protecção de cianças e jovens em perigo; artigo $7^{\circ} \mathrm{A}$ intervenção das entidades com competência em matéria de infância e juventude é efectuada de modo consensual com os pais, representantes legais ou com quem tenha a guarda de facto da criança ou do jovem, consoante o caso, de acordo com os princípios e nos termos do presente diploma; artigo $9^{\circ}$ A intervenção da comissão de protecção das crianças e jovens depende do consentimento expresso dos seus pais, do representante legal ou da pessoa que tenha a guarda de facto, consoante o caso; artigo $10^{\circ}$ 1- a intervenção das entidades referidas depende da não oposição da criança ou do jovem com idade igual ou superior a 12 anos 2- a oposição da criança com idade inferior a 12 anos é considerada relevante de acordo com a sua capacidade para compreender o sentido da intervenção. 
de prestar consentimento. Acresce que nenhum familiar estava presente. A doente foi internada, no entanto, à data em que se apresentava capaz de consentir, o período de tempo preconizado para a colheita de amostras biológicas tinha sido largamente excedido.

$\mathrm{Na}$ opinião da examinanda, tendo em conta que a recolha e preservação dos vestígios pode ser a única forma de identificação do agressor, deviam os peritos médicos ter procedido à recolha de amostras biológicas, armazenando-os até que se encontrasse capaz de tomar decisões, nomeadamente sobre a apresentação de queixa (Carr 2010).

Impõe-se então estabelecer qual a atitude a tomar quando as alterações cognitivas do examinando não são compatíveis com uma recuperação rápida da capacidade para consentir, tal como o que deve ser feito quando é expectável que esta competência seja readquirida num curto período de tempo.

Se é expectável que o examinando recupere a capacidade para consentir num período de horas, parece-nos ideal que se espere por esse momento, antes de proceder à realização do exame. No caso de não ser expectável que o examinando recupere o normal desempenho cognitivo, por um período de tempo considerável, deverá aguardar-se que o tribunal nomeie um representante legal que possa consentir ou recusar o exame forense.

Ocasionalmente a decisão de realização do exame antes do examinando recuperar a consciência, ou antes da nomeação do tutor, é legitimada pela probabilidade das evidências serem destruídas por procedimentos médicos, tais como a inserção de algália ou a lavagem do cabelo e da superfície corporal. É ainda de considerar que a preservação dos vestígios biológicos, nomeadamente de saliva (mordeduras) ou sémen, deve ser assegurada precocemente. Usando como exemplo o caso do abuso sexual com penetração, a zaragatoa bucal deve realizar-se nas primeiras 8 horas, a anal nas primeiras 24 horas e a vaginal até $48 \mathrm{~h}$ após a agressão. Acresce ainda que quando a vítima é encontrada, muitas vezes não é possível determinar há quanto tempo decorreu o abuso, sendo indicado, também nestes casos, que se proceda à colheita de imediato (Magalhães 2010).

É de relevar que nem sempre cabe à vítima ou ao tutor a decisão de apresentar queixa, do alegado crime, à autoridade judiciária. Procede do artigo $242^{\circ}$ do Código de Processo Penal a obrigatoriedade de denúncia ao Ministério Público dos funcionários ${ }^{21}$ quanto a crimes que tomarem

21 Decorre do artigo $386^{\circ}$ do Código Penal que para efeito da Lei penal a expressão funcionário abrange trabalhadores da Administração Pública com qualquer tipo de vínculo. 
conhecimento durante as suas funções ou por causa delas. É referido ainda no artigo $53^{\circ}$ do Código Deontológico da Ordem dos Médicos que sempre que o médico, chamado a tratar um menor, um idoso, um deficiente ou um incapaz, verifique que estes são vítimas de sevícias, maus tratos ou assédio, deve tomar providências adequadas para os proteger, nomeadamente alertando as autoridades competentes. Acresce o ${ }^{\circ} 2$ do artigo $66^{\circ}$ da lei 147/99 de 1 de Setembro que a comunicação é obrigatória para qualquer pessoa que tenha conhecimento de situações que ponham em risco a vida, a integridade física ou psíquica ou a liberdade da criança ou do jovem.

Quando a conduta denunciada é um crime público ${ }^{22}$ basta a sua notícia para que o Ministério Público exerça acção penal, independentemente de qualquer manifestação de vontade por parte do ofendido ou do seu representante legal.

Relativamente aos crimes semi-públicos ${ }^{23}$, a denúncia só dará lugar a instauração de inquérito se a queixa for apresentada no prazo legalmente previsto. Compreende-se assim que neste tipo de crimes assegurar a recolha e preservação de evidências não implica o desencadeamento do procedimento criminal. Garantir a preservação das provas até que o examinando decida se pretende desencadear a investigação criminal é essencial.

\section{COLHEITA DE AMOSTRAS BIOLÓGICAS}

Afirmar que os exames são compulsivos em processo penal significa que as autoridades policiais podem conduzir coactivamente o cidadão para que realize exames médico-legais, desde que requeridos pela autoridade judiciária competente. Se ainda assim o cidadão se recusar não deve o médico perito violar a sua integridade física e moral (Pereira 2005).

Assim quando o examinado não consente na necessária colheita de evidências biológicas há que gerir o conflito entre os direitos fundamentais do indivíduo, nomeadamente o direito à integridade corporal e o direito à

22 Determina o Código Penal como crimes de natureza pública a violência doméstica (art. $\left.152^{\circ}\right)$, maus tratos $\left(152^{\circ}-\mathrm{A}\right)$, coacção sexual $\left(<16\right.$ anos) (art. $\left.163^{\circ}\right)$, violação $(<16$ anos) (art. $164^{\circ}$ ), abuso sexual de pessoa incapaz de resistência $\left(<16\right.$ anos) (art. $\left.165^{\circ}\right)$, abuso sexual de pessoa internada (art. $\left.166^{\circ}\right)$, abuso sexual de crianças ( $0-13$ anos) $\left(\operatorname{art.~} 171^{\circ}\right)$, abuso sexual de menores dependentes (14-18 anos) (art. $172^{\circ}$ ). Acresce o artigo $178^{\circ}$ do Código Penal que se de um crime resultar suicídio ou morte da vítima considera-se também de natureza pública.

23 São definidos no Código Penal como crimes de natureza semi-pública os actos sexuais com adolescentes (entre 14 e 16 anos) (Artigo $173^{\circ}$ ) e os crimes sexuais quando a vítima é maior de idade. 
autodeterminação corporal, e os interesses públicos da descoberta da verdade material e realização da justiça.

Procede do artigo $29^{\circ}$ da Declaração Universal dos Direitos do Homem que o legislador pode estabelecer limites aos direitos fundamentais, para assegurar o reconhecimento ou o respeito dos direitos e liberdades de outrem e das justas exigências da moral, da ordem pública e de bem estar geral numa sociedade democrática. Ressalva, no entanto, o $\mathrm{n}^{\circ} 2$ do artigo $18^{\circ}$ da Constituição da República Portuguesa que a lei só pode restringir os direitos, liberdades e garantias nos casos expressamente previstos na Constituição, devendo as restrições limitar-se ao necessário para salvaguardar outros direitos ou interesses constitucionalmente protegidos.

Com efeito, o nosso ordenamento jurídico prevê várias situações em que estes direitos cedem face a interesses comunitários e sociais preponderantes. Assim sucede quando se impõem certas condutas como a vacinação obrigatória, os radiorrastreios e o tratamento obrigatório de certas doenças contagiosas.

\section{Perícias toxicológicas}

No caso de exames para determinação da alcoolemia em condutores suspeitos de estarem sob a influência do álcool, o Código da Estrada (artigos $152^{\circ}{ }^{24}$ e $153^{\circ}$ do DL 44/2005, de 23 de Fevereiro) prescreve que o condutor apesar de não ser arguido, nem suspeito, tem que se submeter a exames. Poderá verificar-se a necessidade de punção venosa para colheita de sangue nos casos em que seja impossível proceder a pesquisa de álcool no ar expirado. No caso de recusa será o examinado punido por crime de desobediência.

A obrigatoriedade de exames médicos a toxicodependentes é assegurada pelo DL 15/93, de 22 de Janeiro, prescrevendo o artigo $43^{\circ} \mathrm{n}^{\circ} 4$ o dever de sujeição a análise de sangue ou de urina ou outra que se mostre necessária e o artigo $52^{\circ}$ a ordenação de perícia urgente, adequada à determinação do estado de toxicodependência (nomeadamente de análises a que se refere o $\mathrm{n}^{\circ} 4$ do artigo $43^{\circ}$ ) sempre que no decurso do inquérito ou da instrução, haja

24 Artigo $152^{\circ}$ do Código da Estrada 1-Devem submeter-se às provas estabelecidas para a detecção dos estados de influenciado pelo álcool ou por substâncias psicotrópicas a) os condutores; b) os peões, sempre que sejam intervenientes em acidentes de trânsito; c) as pessoas que se propuserem a iniciar a condução 2-(...) 3- as pessoas referidas nas alíneas a) e b) do $n^{\circ} 1$ que recusem submeter-se às provas estabelecidas para a detecção do estado de influenciado pelo álcool ou por substâncias psicotrópicas são punidas por crime de desobediência 4-(...) 5O médico ou paramédico que, sem justa causa, se recusar a proceder às diligências previstas na lei para diagnosticar o estado de influenciado pelo álcool ou por substâncias psicotrópicas é punido por crime de desobediência 
notícia de que o arguido era toxicodependente à data dos factos que lhe são imputados. Acrescenta o $\mathrm{n}^{\circ} 4$ do artigo $53^{\circ}$ que quem, depois de devidamente advertido das consequências penais do seu acto, se recusar a ser submetido a revista ou a perícia, autorizada nos termos do número anterior, é punido com pena de prisão até 2 anos ou com pena de multa até 240 dias.

\section{Perícias genéticas}

A identificação genética é, actualmente, de importância fundamental em Medicina Legal, tanto no que concerne à investigação de filiação biológica de parentesco como à identificação de restos cadavéricos ou de um suspeito (em criminalística).

Assim, este tipo de perícias pode ser invocado não só em sede de investigação criminal, mas também em processo civil, nomeadamente para a realização de testes de investigação biológica da paternidade. De facto, o elevado número deste tipo de perícias deve-se, em parte, à reforma do Código Civil Português em 1977, que regulamentou através do artigo $1864^{\circ}$ a obrigatoriedade de averiguação oficiosa da paternidade nos casos em que o filho é registado apenas com o nome da mãe. Acresce o artigo $1801^{\circ}$ que nas acções relativas à filiação são admitidos como meios de prova os exames de sangue e quaisquer outros métodos cientificamente comprovados (designadamente recorrendo a amostras de epitélio bucal ou raiz de cabelos). Estes testes podem ser solicitados por um juiz, quando integrados num processo judicial, ou realizados de forma directa, fora do processo.

Em Portugal, os testes de paternidade são realizados nos Serviços de Genética e Biologia Forense do Instituto Nacional de Medicina Legal e Ciências Forenses, I.P. (INMLCF, I.P.), nos Laboratórios de Genética Humana e/ou Médica, em Laboratórios pertencentes a Universidades e em Laboratórios privados. Em contexto de processo judicial os exames são realizados, nos termos da lei, no INMLCF, I.P., ou em laboratórios com protocolos de cooperação técnico-científica estabelecidos com este Instituto.

É de referir que em sede de Direito Civil, procede do artigo $519^{\circ}$ do Código do Processo civil o dever de colaboração processual para a descoberta da verdade. Assim numa acção de filiação também impende sobre o examinando o dever jurídico de realizar exames genéticos. No caso de recusa pode aplicar-se uma condenação em multa, bem como proceder-se a inversão do ónus da prova ${ }^{25}$,

25 Artigo 344 n² do Código Civil determina que há inversão do ónus da prova quando a parte contrária tiver culposamente tornado impossível a prova ao onerado, sem prejuízo das sanções que a lei de processo mande especialmente aplicar à desobediência ou às falsas declarações. 
ou seja, assume-se como provada a filiação biológica, sendo da competência do presumido pai elidir esta presunção legal.

\section{Considerações gerais}

Em termos legais discute-se a legitimidade da recolha de material biológico, contra a vontade do examinado, considerando os bens jurídicos lesados.

Paulo Mota Pinto sublinha que o Direito ao desenvolvimento da personalidade não protege apenas a liberdade de actuação, mas igualmente a liberdade de não actuar, não tutelando, neste sentido, apenas a actividade, mas igualmente a passividade, com uma garantia não unidimensional de actuação, mas pluridimensional, de liberdade de comportamento, enquanto decorrente da ideia de desenvolvimento da personalidade (Mota Pinto 1999).

Acredita Costa Andrade, tomando como exemplo a colheita de células epiteliais da mucosa bucal, através da introdução de uma zaragatoa, que se deve considerar ameaçada a inviolabilidade da integridade moral e física da pessoa, imposta no artigo $25^{\circ}$ da Constituição da República Portuguesa. Considera o autor que esta conduta, ainda que não lesiva ou atentatória da saúde não deixa de ser uma "intromissão para além das fronteiras delimitadas pela pele ou pelos músculos" e portanto não pode deixar de ser compreendida como uma invasão da sua integridade física (Costa Andrade 2004).

Por outro lado, Gomes Canotilho argui que a recolha de material biológico para análise, embora possa ser entendida como uma restrição do direito à integridade pessoal não colide com nenhuma das suas dimensões essenciais, podendo justificar-se de acordo com critérios de proporcionalidade, desde que em ordem à prossecução de uma finalidade constitucionalmente legítima.

Consideramos ser inequivocamente de valorizar, em Direito Penal, o confronto com valores preponderantes, como o direito à vida ou à segurança de terceiros. Aceitamos a doutrina maioritária que considera a colheita de sangue e a ou de raízes de cabelos responsáveis por lesões insignificantes e reversíveis da integridade pessoal (física e moral) e a recolha de células epiteliais da mucosa bucal ou a utilização de amostras de urina não susceptível de se considerar uma ofensa à integridade corporal do examinando, mas tão só ao direito à autodeterminação corporal, e em grau ou medida desprezível, isto é, irrelevante. 
A obrigação de submissão a exames em processo penal é, de acordo com o Princípio da Proporcionalidade ${ }^{26}$, defensável em crimes muito graves ou quando mais nenhuma prova possibilita determinar o culpado do crime. Um facto a considerar é que de acordo com o artigo $80^{\circ}$ do Código $\mathrm{Penal}^{27}$, à privação momentânea da liberdade e restrição dos direitos fundamentais, impostas ao arguido, deve corresponder um desconto na pena prisão. Segundo Paulo Pinto de Albuquerque deve descontar-se um dia de prisão por cada dia de detenção para submissão a exame médico-legal/forense, independentemente do número de horas que a detenção tenha durado, em cada dia.

Do exposto resulta dificuldade de aceitar que no âmbito do Direito Civil se possa da mesma forma obrigar o examinando a submeter-se a perícias genéticas. É de relevar não só a forte influência do Princípio do Dispositivo ${ }^{28}$ em Processo Civil como o facto de não serem contempladas neste âmbito sanções com privação de liberdade impossibilitando uma espécie de ajuste como o acima descrito.

Mesmo no âmbito penal há que interpretar cum grano salis estas considerações, devendo distinguir-se o recurso a condutas médicas inócuas para obtenção da amostra (sendo em regra este o caso) de actuações que possam pôr em risco a saúde do examinando.

A título de exemplo, quando em contexto de acidente de viação que implique assistência médica hospitalar ou mesmo internamento, a realização de colheitas de sangue para efeitos de diagnóstico é comum, sendo de presumir o consentimento ainda que tácito do sinistrado, destinando-se esta conduta a promover a sua saúde. Apesar de poder parece lícito nestes casos usar parte dessa amostra para as pesquisas toxicológicas forenses, o confronto entre o consentimento informado e a imposição legal volta a colocar-se, dados os diferentes fins a que se destinam as amostras. No entanto, se do procedimento de colheita de material biológico, que se destina à produção de provas, não resultar qualquer risco para a saúde do examinando, enquadrando a recusa à sua submissão uma atitude de obstrução à Justiça, somos de opinião que é de

26 Princípio que assegura que os meios utilizados pelo legislador são adequados e exigíveis à consecução dos fins visados. O meio é adequado se, com a sua utilização, o evento pretendido pode ser alcançado e é exigível se o legislador não dispõe de outro meio eficaz, menos restritivo aos direitos fundamentais.

27 Artigo $80^{\circ}$ do Código Penal 1- A detenção, a prisão preventiva e a obrigação de permanência na habitação sofridas pelo arguido são decontadas por inteiro no cumprimento da pena de prisão(...)

28 Princípio que assegura a autonomia das partes na definição dos fins que elas procuram obter através da acção pendente 
aceitar que se proceda à colheita, desde que judicialmente determinada, mesmo na ausência de consentimento. Não parece deontologicamente tolerável que o médico perito seja conivente com atitudes que servem apenas o objectivo de prejudicar o apuramento dos factos. É de salientar que o exame médico-legal muitas vezes é essencial à resolução de processos-crime relevantes.

Obviamente, nos casos extremos em que o comportamento do examinando o coloca em risco de sofrer lesões durante o exame ou quando coloca em risco a integridade do médico perito, deve a perícia ser deferida para um momento mais adequado, se possível.

Por outro lado, se do acto médico pericial resultarem riscos para o examinando, deve o médico ponderar seriamente a realização da perícia, ainda que judicialmente determinada, podendo solicitar um parecer à Ordem dos Médicos, se adequado. Importa respeitar as boas práticas éticas e deontológicas.

\section{BASE DE DADOS DE PERFIS DE ADN}

De acordo com o $n^{\circ} 1$ do artigo $6^{\circ}$ da lei $n^{\circ} 5 / 2008$, a base de dados de perfis de ADN é construída, de modo faseado e gradual, a partir da recolha de amostras em voluntários, para o que devem prestar o seu consentimento livre, informado e escrito. $\mathrm{O}$ artigo $7^{\circ}$ determina que a recolha de amostras em pessoas para fins de identificação civil, designadamente em parentes de pessoas desaparecidas, carece de consentimento livre, informado e escrito e que quando se trate de menores ou incapazes, a recolha de amostras depende de autorização judicial.

No que concerne à base de dados criminal, respeitando a privacidade individual, a legislação portuguesa prevê que sejam inseridos apenas os perfis de condenados com penas concretas iguais ou superiores a três anos.

Existe ainda um ficheiro contendo os perfis dos profissionais que procedem à recolha e análise das amostras, sendo o consentimento (prévio) obrigatório para o desempenho de funções enquanto técnico de recolha e análise de amostras de ADN.

Assim, com as devidas excepções de obtenção de amostras em sede de processo penal e de inserção de perfis de ADN na base de dados criminal, quando cumprido o critério de inclusão descrito, qualquer colheita para a obtenção de um perfil genético deve sempre ser precedida de consentimento do titular. Este consentimento contempla não só a colheita da amostra, mas 
também a inclusão do perfil numa base de dados, com conhecimento das finalidades da existência dessa base, dos tipos de investigação a desenvolver, dos riscos e benefícios potenciais, das condições e duração do armazenamento, as medidas tomadas para garantir a confidencialidade dos dados e da previsão quanto à possibilidade de comunicação ou não dos resultados obtidos com aquele material.

No entanto a informação genética reveste-se de particularidades importantes, não estamos perante um simples dado pessoal mas perante um dado familiar (Moniz 2002). Assim a restrição do direito à privacidade recai não só sobre a pessoa que nele consente, mas também sobre os indivíduos geneticamente relacionados, igualmente titulares desses dados genéticos.

Tendo em conta estas singularidades encontra-se legislada a obrigatoriedade de utilização exclusiva dos perfis de ADN para fins de identificação ${ }^{29}$. Ou seja, não é permitida a sua utilização para inferência de características físicas, ficando também de fora a utilização de marcadores que permitam identificar predisposições genéticas, nomeadamente tendência para determinada doença. Está ainda estabelecido que caso seja encontrada uma associação entre um marcador até agora considerado não codificante e uma doença ou um traço comportamental, este deverá ser retirado do painel e todos os dados que tenham sido obtidos anteriormente com esse marcador deverão ser eliminados.

No entando a partir da comparação de perfis genéticos das bases de dados é possível afirmar ou negar relações familiares entre os dadores. Com efeito a comparação de um perfil genético obtido a partir de um vestígio do local do crime com um perfil da base de dados de ADN permite inferir se existe uma relação familiar próxima entre o dador e o culpado, ou seja, é possível perceber que se trata de um irmão ou de um filho desse dador, ainda que o seu perfil não conste da base de dados. Estas inferências devem ser analisadas no estrito cumprimento da lei, salvaguardando-se sempre o necessário sigilo judicial.

Tendo em conta estas preocupações assegura o legislador que a informação pessoal do dador se encontra numa base separada da base de dados de perfis de ADN, as quais são manipuladas por diferentes utilizadores em lugares distintos.

Todas estas problemáicas, efectivas ou potenciais, à presente data, colocam em causa a validade do consentimento livre e esclarecido no contexto de armazenamento de informação genética.

29 Art. $1^{\circ}$ Lei $n^{\circ} 5 / 2008$ de 12 de Fevereiro refere que a presente lei estabelece os princípios de criação e manutenção de uma base de dados de perfis de ADN, para fins de identificação (...) 


\section{O CONSENTIMENTO NO CONTEXTO DE ABUSO SEXUAL}

Sempre que o examinando está inconsciente ou desorientado, sendo incapaz de fornecer a história do evento traumático (e de consentir), é importante verificar se existe informação pré-hospitalar ou achados no exame físico inicial que sugiram a ocorrência de abuso sexual. Sempre que se verifique essa suspeita o exame ano-genital deve integrar a normal avaliação clínica.

Segundo Pierce-Weeks deve considerar-se a possibilidade de ocorrência de abuso sexual sempre que: haja testemunhas que relatam abuso sexual perpetrado em examinando inconsciente; o examinando seja encontrado meio despido, sem explicação aparente (principalmente se a região ano-genital se encontrar exposta); a roupa interior esteja ausente; existam marcas de mordeduras na superfície corporal do examinando (principalmente se em áreas do corpo pouco acessíveis); sejam notadas lesões ano-genitais recentes; se verifiquem outras lesões importantes, tais como lesões figuradas, queimaduras, estigmas ungueais (nomeadamente no pescoço) ou marcas de manietação (nos punhos e tornozelos), sem explicação aparente; o cabelo esteja cortado ou rapado; haja suspeita de violência doméstica.

Nestes casos, procedimentos inócuos para a saúde do examinando, tais como pentear os pêlos púbicos e realizar zaragatoas ano-genitais, orais e da superfície corporal com o propósito de preservar eventuais vestígios, devem ser realizados antes das condutas de higiene ou de manipulação clínica. Quando as amostras de sangue e urina são colhidas para avaliação de rotina poderão parte delas seguir para avaliação toxicológica de carácter forense, sem qualquer necessidade de procedimento invasivo extra. Colhidas as evidências o examinado terá mais tarde, quando cognitivamente capaz, a possibilidade de as utilizar em processo de investigação criminal no caso de optar por fazer queixa do crime.

Cumpre-nos ainda analisar detalhadamente os pressupostos do consentimento informado, no caso de abuso sexual de menores. Consta no regime da lei e da portaria sobre educação sexual e planeamento familiar, que deve admitir-se $o$ acesso livre às consultas (de planeamento familiar), sem restrições como a que resultaria da necessidade de uma autorização prévia dos pais ${ }^{30}$.

30 Tal resulta do artigo $5^{\circ}$ da lei $n^{\circ}$ 3/84, de 24 de Março: "É assegurado a todos, sem discriminações, o livre acesso às consultas e outros meios de planeamento familiar"; e da Portaria $\mathrm{n}^{\circ}$ $52 / 85$, de 26 de Janeiro, que regulamentou os chamados centros de atendimento para jovens e previu o acesso, sem quaisquer restrições, de todos os jovens em idade fértil. 
Encontramos aqui uma importante excepção à sujeição dos menores ao poder paternal, em matérias relativas à informação sexual e à contracepção. Esta premissa poderá estender-se ao exame pericial de âmbito sexual. Consideramos assim que se o menor for capaz de compreender o alcance, a índole e as consequências deste exame e da sua recusa, poderá consentir ou dissentir sem o conhecimento dos pais.

Não obstante, por se tratar de um crime contra a autodeterminação sexual ou contra a liberdade sexual em que a vítima é menor de idade, considera-se de natureza pública, pelo que o desencadeamento da acção penal não depende da vontade do menor. No entanto e sem colocar em causa a necessidade de proceder criminalmente contra quem comete um crime, perante determinadas circunstâncias poderá ser desaconselhável, do ponto de vista do interesse da criança ou do jovem, desencadear o procedimento criminal, devendo ponderar a entidade judiciária a divergência ou a incompatibilidade entre as necessidades da criança e a acusação/punição do agressor.

Frequentemente depara-se o perito médico com alegações de abuso sexual de menores em contexto de divórcio litigioso e regulação do poder paternal. Segundo o artigo $1906^{\circ}$ do Código Civil, sobre o exercício das responsabilidades parentais em caso de divórcio, separação judicial de pessoas e bens, declaração de nulidade ou anulação de casamento, as responsabilidades parentais relativas a questões de particular importância para a vida do filho são exercidas em comum por ambos os progenitores, salvo nos caso de urgência manifesta em que qualquer um dos progenitores pode agir sozinho, devendo prestar informações ao outro logo que possível. No entanto sempre que o exercício comum das responsabilidades parentais for julgado contrário aos interesses do filho, deverá o tribunal, através de decisão fundamentada, determinar que essas responsabilidades sejam exercidas por um dos progenitores. É de sublinhar que o artigo $69^{\circ}$ da Constituição da República Portuguesa vincula o exercício do poder paternal aos interesses do filho proibindo que os pais o exerçam no seu próprio interesse. Acresce o artigo $36^{\circ}$ que, mediante decisão judicial, os filhos podem ser afastados dos pais quando estes não cumprem os seus deveres fundamentais.

Deverá, a nosso ver, considerar-se a realização do exame pericial sem a necessidade do consentimento do progenitor que tem a guarda de facto do filho, quando sobre este recai a suspeita de abuso.

No entanto a situação mais comum é a criança ser levada à Urgência pelo progenitor a que tem a sua guarda de facto, quando esta regressa de uma visita, não supervisionada, ao outro progenitor. Se por vezes a história e os 
achados do exame objectivo são sugestivos dos factos descritos, situações há em que a criança é observada no Serviço de Urgência sempre que regressa da visita a um dos progenitores, não resultando no entanto qualquer evidência médico-legal dos exames periciais realizados, não sendo de negligenciar o carácter intrusivo dos mesmos. É possível que alguns destes casos correspondam a falsas alegações, existindo um conjunto de indicadores que podem contribuir para esta suspeita, nomeadamente relatos de vários episódios de abuso sobreponíveis e discurso da criança parco em detalhes. Consideramos que a sujeição repetida e vã a este tipo de exames, entrando em confronto diferentes interesses e direitos da criança.

Como já foi referido, as perícias médico-legais urgentes podem realizar-se previamente ao processo de inquérito penal ou a uma denúncia de crime a órgão de polícia criminal, com o intuito de assegurar a recolha e a preservação dos meios de prova. No entanto, nestes casos o progenitor que denúncia encontra-se sob um importante conflito de interesses. Veríamos com bons olhos que, existindo mais do que uma perícia sexual prévia, por semelhantes alegações e não tendo as mesmas sido conclusivas, se fizesse apenas a denúncia aguardando-se instruções do Tribunal. Entendemos que esta entidade terá forma de avaliar melhor a situação, uma vez que a acção penal terá sido desencadeada na sequência da primeira denúncia. Se a entidade judicial entender necessário a realização novo exame, este teria então lugar na Delegação ou Gabinete Médico-Legal da respectiva área.

\section{OS CORREIOS DE DROGA}

Podemos considerar que a capacidade para consentir dos correios de droga está comprometida por vários factores, nomeadamente o temor de represálias por parte dos cúmplices e o medo de intoxicação por estupefacientes. $\mathrm{O}$ facto do examinando se encontrar sob custódia judicial, muitas vezes associado a falsas expectativas de libertação precoce, em troca de colaboração ou o receio de que a recusa a submeter-se a exame médico-legal possa ser considerada uma confissão tácita de culpa, influi nas suas decisões.

Assim para que o princípio da autonomia seja respeitado nestes casos é necessário que lhe seja dada a possibilidade de escolher de uma forma informada e que essa escolha seja individual e livre. Roberts enfatiza a importância do acto voluntário, ou seja, a possibilidade do examinando actuar de acordo com a sua opinião acerca do que é correcto e que melhor se adapta à sua situação actual e aos seus valores. O acto voluntário implica capacidade para tomar decisões livremente e na ausência de coacção. É assim perceptível 
que os conceitos de livre arbítrio e livre escolha se associam intimamente na noção de consentimento informado.

Recai sobre o perito o dever de explicar os objectivos do exame forense e as repercussões da sua recusa e de garantir, na medida do possível, a privacidade do examinando durante todo o processo.

É de observar com alguma cautela a realização de procedimentos que não resultarão em benefício clínico directo para o examinado, podendo até alguns deles colocar em risco a sua saúde.

A realização de intervenções invasivas sem indicação médica não cumpre os critérios da leges artis. Com efeito a utilização da endoscopia para localizar os pacotes com droga confere riscos para a saúde do examinado, designadamente obstrução ou perfuração intestinal. Mesmo o recurso a métodos, minimamente invasivos que aceleram o trânsito intestinal, tais como enemas, não se considera indicado nestes casos, pois aumentam o risco de ruptura dos pacotes, com consequente intoxicação por libertação do estupefaciente. Portanto, ainda que o examinando consinta na realização destas condutas, tendo em conta que as mesmas não se revestem de benefícios clínicos, constituirão uma ofensa à integridade física se delas resultar danos desse bem jurídico.

Outro exemplo é a utilização de anestesia geral para proceder a exame ano-genital, quando a droga é acondicionada na cavidade vaginal ou no recto e o examinando recusa o exame pericial. Se por questões clínica o examinando tiver que ser sedado por outras razões, que não o da colheita de evidências, o exame pericial deve ser realizado como complemento dos restantes procedimentos necessários. No entanto a sedação não deverá ser utilizada com o único propósito de realizar um exame não emergente, por ausência de consentimento, uma vez que este tipo de medicação se associa a riscos para a saúde, não passíveis de serem negligenciados. Se ocorrer um problema, quem será responsável pelas consequências? (Corte Real 2011)

Consideramos então que durante o examine de um correio de droga a prioridade é evitar complicações médicas. Os interesses da entidade judicial devem ser considerados, na medida do possível, não podendo no entanto sobrepor-se a um dos deveres primordiais do médico, o de zelar pelo bem estar (físico e moral) do examinando.

A atitude mais correcta parece-nos ser a de monitorização do examinando durante a passagem espontânea dos pacotes, em serviço hospitalar adequado, designadamente na Unidade de Cuidados Intensivos. 
Apesar de estarmos perante suspeitos de crime devemos aceitar o argumento Kantiano de que existe um dever de "agir por forma a usar a humanidade, quer na sua pessoa como de qualquer outra, sempre ao mesmo tempo como fim e nunca meramente como meio".

Relembramos também o já referido artigo $124^{\circ}$ do Código Deontológico da Ordem dos Médicos que apela à estrita utilização de meios de exame que não sejam prejudiciais ao examinando, durante o acto médico pericial.

Por outro lado, quando a actuação do médico perito não implica riscos para a saúde do examinando, por exemplo no caso de transporte de droga na cavidade vaginal ou rectal, mas ainda assim este não consente a realização do exame, apesar de não defendemos o uso da força ou coacção, tal recusa deve ser apreciada e alvo de decisão pela autoridade judicial. Não existe nestes casos qualquer tipo de constrangimento de ordem deontológica, que se oponha à realização da perícia.

Em casos extremos, em que o examinando se torna violento, colocando em risco a sua integridade física ou a do médico perito, podem justificar-se intervenções médicas emergentes, não consensuais (Baljevic 2011), nomeadamente com recurso à sedação.

Importa que o médico perito possa decidir de forma autónoma a conduta mais adequada a implementar, tendo em conta a leges artis. É sempre possível o recurso à Ordem dos Médicos ou a um Tribunal Superior (como entidades mediadoras), em situações de conflito entre ordens judiciais e princípios éticos ou deontológicos relevantes na actividade pericial.

O recurso à figura do médico perito não pode servir somente o objectivo de garantir o sentimento de pudor, na vertente técnica do exame forense. Com efeito o seu principal papel é assegurar o respeito pela saúde e integridade psicofísica do examinado, no contexto do solicitado apoio à Justiça.

\section{REFERÊNCIAS}

Andrade MC. Direito Penal Médico. Coimbra: Coimbra Editora; 2004.

Baljevic M, et al. Ethics of medical care for body packers (drug smugglers): untangling a web of fears and conflicts of interest. Eastern Mediterranean Health Journal. 2011. 17 (7): 625-29.

Carr M, et al. Developing a policy for sexual assault examinations on incapacitated patients and patients unable to consent. Journal of Law, Medicine and Ethics. 2010. 38 (3): 647-53. 
Corte Real F. The medical expert: some deontological issues. World Association for Medical Law Newsletter. 2011. 3: 9.

Department of Justice, Office on violence against woman . A national protocol for sexual assault medical forensic examinations adults/adolescentes; 2004. p. 49-52.

Kant I. Fundamentação da metafísica dos costumes. Tradução por Antônio Pinto de Carvalho. Lisboa: Companhia Editora Nacional; 1964.

Lee P. In the absence of consent sexual assault unconscioussness and forensic evidence. British Columbia Centre of Excellence for Women's Health; 2001. p. 1-61.

Magalhães T. Abuso de crianças e jovens. Lisboa: Editora Lidel; 2010.

Magalhães T, Ribeiro C (Instituto Nacional de Medicina Legal, IP). Recomendações gerais para a realização de exame em casos de suspeita de violência doméstica, maus tratos ou crimes sexuais contra crianças e jovens de menor idade. INML,IP; 2010. Norma Procedimental. $\mathrm{N}^{\mathrm{o}} 1.5$

Meneses R. Principalismo e pedagogia: entre a ética e a educação. Eukasia, Revista de Filosofia 2007. 3 (14) : 189-216.

Moniz H. Os problemas jurídico-penais da criação de uma base de dados. Revista Portuguesa de Ciência Criminal 2002. 12 (2): 237-264.

Neto L. Os limites da Ciência do Direito. Interacções. 2006. 3: 4-18.

Nietzsche F. Humano, demasiado humano. Tradução por Paulo Osório de Castro. Círculo de Leitores; 1996.

Nietzsche F. Para além do bem e do mal. Tradução por Carlos Marujão. Círculo de Leitores; 1996.

Pereira A. Novos desafios da responsabilidade médica: uma proposta para o Ministério Público. Direito e Sociedade - Revista do Ministério Público do Estado do Paraná. 2004. 3 (2): 35-58.

Pereira A. O Consentimento (Informado) na Actividade Pericial Forense. Revista Portuguesa do Dano Corporal. 2005. 14 (15): 11-45.

Pinto PM. O Direito ao livre desenvolvimento da personalidade. In: Portugal - Brasil, ano 2000. Separata de Studia Iuridica. Coimbra: Coimbra Editora; 1999. Vol. 40. p. 149-246.

Ramos HV. Ars Medica, técnica e ética. Acção Médica. 2011. 75 (2): 20-32.

Rollero M. Sobre el acto médico. Asociación Española de Bioética y Ética Médica. Cuadernos de Bioética. 2003. 50 (1): 25-38.

Roth LH, et al. Tests of competency to consent to treatment. American Journal of Psychiatry. 1977. 134 (3): 279-84.

Serrão D. Para uma Deontologia não oportunista. Acção Médica. 2008. 72 (3): 5-10.

Wear S. Informed consent. In: Khushf G, ed. Handbook of Bioethics. New York: Kluwer Academic Publishers; 2004. p. 251-90.

Resumo: Dilemas éticos do consentimento informado em Ciências Forenses

A prática médica engloba actividades tão diversas quanto complexas. 0 médico pode ser chamado a actuar como perito, ao serviço da Justiça, para que estabeleça, por meio de obtenção de provas, a veracidade ou falsidade dos factos alegados. 
As características do exame pericial colocam muitas vezes o médico em situações de conflito entre os interesses do examinando e os do sistema judicial. 0 perito médico lida com pessoas particularmente fragilizadas, cuja capacidade de autodeterminação, logo de consentimento livre e esclarecido, está afectada. Assim o principal mecanismo regulador do Principialismo, o consentimento, não consegue por si só garantir a ética da actividade pericial.

Partindo destes pressupostos os autores reflectem sobre algumas questões: Poderá nalguma situação justificar-se a realização de perícias médico-legais sem o consentimento do examinando, para assegurar meios de prova? Deverá o perito realizar procedimentos sem indicação médica, durante um exame pericial, se o examinado consentir? 0 facto do examinando ser a vítima ou o suspeito deverá relevar na tomada de decisão do perito médico?

Se estas questões se enraízam em princípios inquestionavelmente éticos, as soluções deverão não só contempla-los, mas transcende-los. Emerge a necessidade de harmonizar os preceitos deontológicos do perito com a legislação vigente.

Palavras-Chave: Consentimento informado; actividade pericial.

Summary: Ethics and informed consent in Forensic Sciences

The medical practice associates diverse as well as complex duties. Physicians are expected not only to solve health problems but also to deal with medico-legal issues. Thus the physician may have to give an expert opinion based on evidences, in the name of Justice, to demonstrate the truth or falsehood of the alleged facts. But there are situations of conflict between the examinee interests and those of the legal system.

The vulnerability of the examinees in the forensic setting can impair their autonomy and self-determination, which are essential features to consent a medical act. This fact may compromise the respect of important bioethical principles in medico-legal activity. Regarding this matter some some questions arise: Should the medical expert perform the exam to preserve evidences if the examinee does not consent? Should the physician use any kind of procedures, regardless of their risk, if the examinee consents? The examinee being the victim or the suspect should influence those decisions?

These questions undeniably rely on ethical principles but the answers should not only consider but also transcend them. In medico-legal activity it is essential to balance the ethical principles with the law assumptions.

Key-Words: Informed consent; medico-legal activity.

Pedido de separatas:

BÁRBARA SANTA ROSA

santa.rosa.b@gmail.com 